This review is intended as an educational exercise and reports the personal views of the authors

\title{
IUDs: Which device?
}

Jo Dennis, MFFP, MRCGP, Career Grade Trainee, Abacus Centres for Family Planning and Reproductive Health, Liverpool, UK; Naomi Hampton, MRCOG, MFFP, Formerly Consultant in Reproductive Health Care and Community Gynaecology, Enfield, Middlesex,UK. E-mail: naomi@pol.pl

\section{How to use a FACT}

A FACT is an up-to-date review of a subject relevant to the speciality, intended to help you fulfil your CPD requirements in your home or place of work. Whilst FACTs are edited and reviewed at various levels within the Faculty, the actual contents and views expressed are those of the authors and not the Faculty. More specifically, these reviews are not guidelines. The CEC is producing clinical guidelines separately.

FACTs have three sections: a review, a true/false test, and discussion points. To use a FACT to earn CPD credits you should do the following:

1. Working alone: Read the review and do the test on page 00. The answers are provided on page 00 so you can mark yourself. If there are points you are unsure about, disagree with, or need further clarification on, make a note of these for use at a later date. This should take you no more than 1 hour. Keep a record of having done this in your CPD diary and, unless indicated otherwise on the FACT, this will earn you 1 hour (DFFP), 1 credit (MFFP).

2. Working as a group: Arrange a meeting of at least 1 hour with colleagues to discuss the discussion points given in the FACT (page 00) and any issues the participants have come up with as a result of reading the FACT. Keep a record of having done this in your CPD diary and, unless indicated otherwise on the FACT, this will earn you 1 hour (DFFP), 1 credit (MFFP).

\section{Introduction}

The intrauterine device (IUD) is one of the most commonly used forms of contraception, with an estimated 110 million users worldwide, almost half of these in China. IUDs are used by approximately $5 \%$ of contraceptors at present in the UK. ${ }^{1}$

In long-term use, the primary mode of action of copperbearing IUDs is prevention of fertilisation. The number of sperm reaching the Fallopian tubes is reduced, sperm motility is disrupted and ova development is impeded. In tubal washings from IUD users cleaving fertilised ova are not seen. ${ }^{2}$ Successful implantation, evidenced by the presence of beta-human chorionic gonadotrophin ( $(3-\mathrm{hCG})$ in blood and urine, is rare in copper IUD users. ${ }^{3}$ The prevention of implantation, as a result of biochemical and histological changes in the endometrium, plays only a minor role; the primary mechanism of action of IUDs is interference with fertilisation rather than implantation. ${ }^{4}$ The levonorgestrel-releasing intrauterine system (LNG IUS) works primarily by causing endometrial suppression and by changing cervical mucus and utero-tubal fluids which impairs sperm migration. Anovulation occurs in some women during the first year of use..$^{5}$

The ideal intrauterine method should provide excellent contraceptive efficacy with minimal nuisance or risk of health-threatening side effects. Choice of device depends on many factors including benefits and risks, familiarity, experience and choice of the clinician, cost and availability within the service.

\section{The evidence}

Figure 1 illustrates the devices currently available in the UK, and Table 1 lists the devices with cost and licence of use. All devices are listed on the Drug Tariff and may 
therefore be prescribed by general practitioners (GPs) on FP10. The Medical Devices Agency (MDA) collects and reviews adverse incidents involving medical devices. It is good clinical practice to report all serious adverse events (perforations, pregnancies, limb/thread breakages) associated with any IUD to the MDA. Problems with the LNG IUS should be reported to the Medicines Control Agency (MCA).

Table 1 Intrauterine devices (IUDs) currently available in the UK

\begin{tabular}{|c|c|c|}
\hline Device & Cost $(\mathfrak{f})^{\mathrm{a}}$ & Licence (years) ${ }^{b}$ \\
\hline T Safe $380 A^{\circledR}$ & 9.40 & 8 \\
\hline Multiload $375^{\circledR}$ & 9.24 & 5 \\
\hline Multiload $250^{\circledR}$ and $250^{\circledR}$ short & 7.13 & 3 \\
\hline Nova T200 ${ }^{\circledR c}$ & 10.45 & 5 \\
\hline Nova T380 ${ }^{\circledR}$ & 13.50 & 5 \\
\hline Flexi-T300 ${ }^{\circledR}$ & 8.65 & 5 \\
\hline GyneFix® & 24.75 & 5 \\
\hline LNG IUS (Mirena ${ }^{\circledR}$ ) & 89.25 & 5 \\
\hline
\end{tabular}

${ }^{a}$ British National Formulary, September 2001.

${ }^{b}$ Any copper IUD inserted after age 40 years may be left in situ until after the menopause.

${ }^{\mathrm{c}}$ Withdrawn from the UK market by the manufacturer in October 2001

\section{T Safe $380 A^{\circledR}$}

The Copper T380 series consists of three devices: the $\mathrm{T} 380 \mathrm{~A}$, the original device; the T380Ag, developed and distributed in Finland; and the T380S (Slimline), developed in Canada and distributed in Canada and the UK. All bear a total of $380 \mathrm{~mm}^{2}$ copper. Most of this is as copper wire wound tightly around the central stem. The remainder is as a pure copper collar on each of the horizontal arms.

The Slimline was so called because the copper collars on the side arms were sunk into and thus flush with the side arms, making loading into the insertion tube easier. In 1999, production ceased - for commercial rather than medical reasons. Since then, the T Safe $380 A^{\circledR}$, identical to the Copper T 380A, has become available in the UK.
The T Safe $380 A^{\circledR}$ is now supplied with a sterile loading cap, to aid loading of the side arms into the introducer without the need for sterile gloves. The side arms will only load up to the level of the copper collars, which stand proud, making the diameter presented to the cervix greater than that of the Slimline, this makes insertion more difficult in some cases. A Slimline version has been marketed again in the UK very recently. The current licence for the T Safe $380 \mathrm{~A}^{\circledR}$ is for up to 8 years, although there is no clinical reason why the device should not be used in the same way as the Slimline and T380A, for 10 years.

In 1978, the World Health Organization (WHO) set up randomised multicentre studies in parous women comparing the T380A, the Nova T200 ${ }^{\circledR}$ and the Multiload $250^{\circledR}$ to the $\mathrm{TCu} 220 \mathrm{C}$, a collared device commonly used at the time but now only used in China. ${ }^{6}$

As a result of the excellent performance of the T380A and the T220C, follow-up in this arm of the study was continued for 12 years. $^{7}$ Over 7000 woman-years of follow-up were accumulated for the T380A device and 17000 for the T220C. Both devices performed well in terms of pregnancy prevention. The T380A had significantly lower pregnancy rates at all stages of use, with no pregnancies beyond the eighth year. The cumulative pregnancy rate at 12 years was 2.2 per 100 users, of which 0.4 were ectopic pregnancies.

Rates for other events did not differ significantly between the two devices. Approximately 40\% of T380A devices were removed for medical reasons (including bleeding, pain and pelvic infection) over the 12 years. No uterine perforations were reported with the T380A. Results of this and other studies mentioned are summarised in Table 2 .

As a result of this study, the WHO concluded that the T380A device rivals female sterilisation for long-term pregnancy prevention, with the advantage of being easily reversible. They added that further research into IUDs should be aimed not at increasing efficacy, but at improving the side effect profile, reducing the rates of bleeding, pain and expulsion. Since this landmark WHO study, the Gyne

Figure 1 Intrauterine devices (IUDs) available in the UK. Illustrated from left to right: Mirena ${ }^{\circledR}$, GyneFix ${ }^{\circledR}$, Nova T380 ${ }^{\circledR}$, Gyne T380 ${ }^{\circledR}$ (TCu $380 S$ ), T Safe Cu380A ${ }^{\circledR}$, Flexi-T300 $^{\circledR}$ and Multiload Cu375 ${ }^{\circledR}$






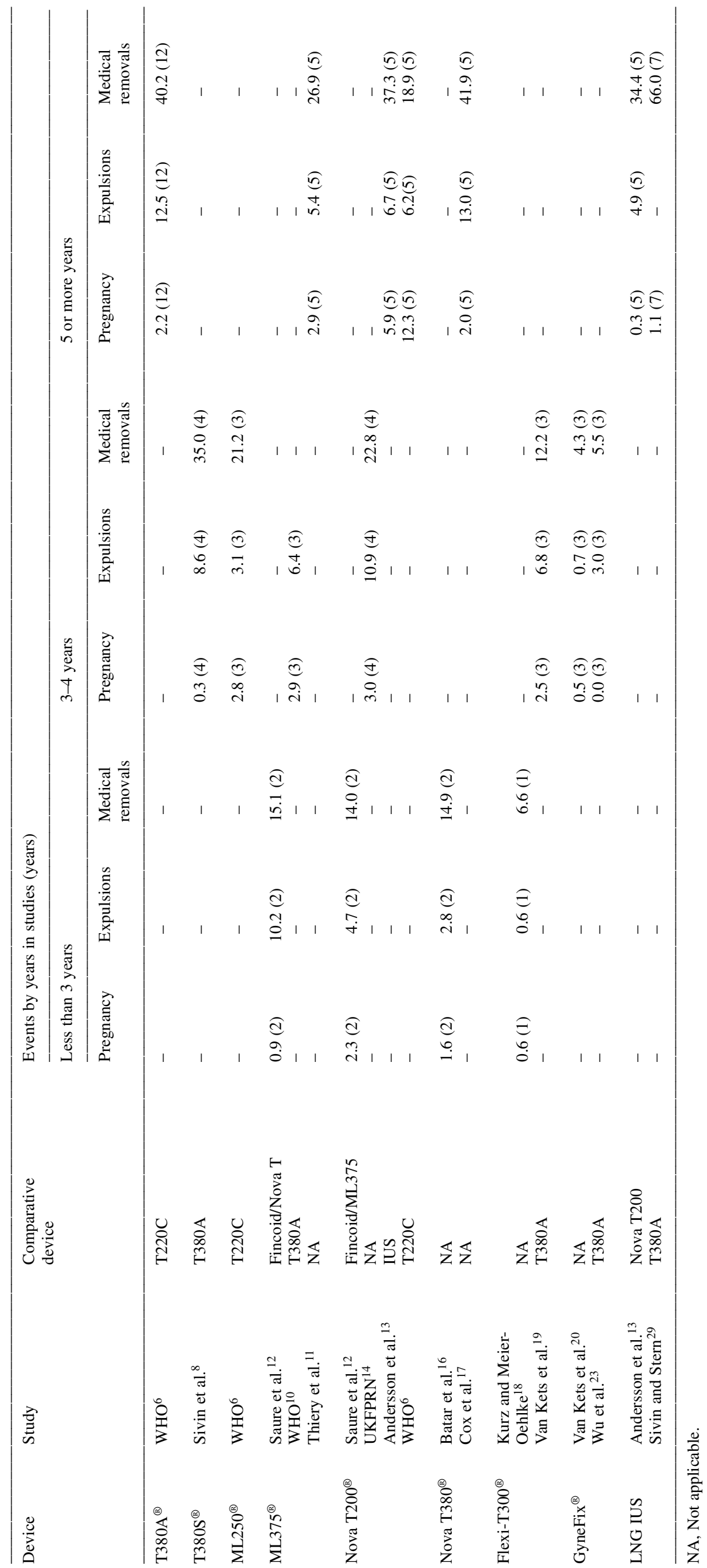


T380 has been accepted as the 'gold standard' device against which others are measured.

The T380S was compared to the $\mathrm{T}_{380 \mathrm{~A}^{8}}$ in a 4-year randomised study. The results showed the Slimline to be superior to the T380A in pregnancy prevention but to have a higher expulsion rate in the first year of use. This latter finding was thought to be a function of the anomalously low expulsion rate of the T380A in this study compared to others, rather than a higher than average expulsion rate with the $\mathrm{S}$ version. The lower pregnancy rate with the Slimline may again be anomalous, or may be related to the more lateral placement of the copper collars on the side arms, bringing the copper closer to the tubal ostia. A very large further study would be needed to clarify this. The study concluded that both versions provide effective pregnancy prevention.

\section{The Multiload devices}

The Multiload (ML) series of devices was designed to reduce the incidence of expulsion by the addition of plastic fins on the lateral, curved arms. Copper wire is wound onto the central stem of the device. The ML $250^{\circledR}$ was the first version, available in three sizes (standard, mini and short), to allow insertion into different sized uteri including the nulliparous. The ML375 ${ }^{\circledR}$ followed, with more copper to enhance efficacy and length of use. Insertion is by a pushin technique, the arms of the device remaining outside the inserter tube. The lower copper-load versions are licensed for 3 years' use and the 375 model for 5 years, although efficacy to 8 years has been demonstrated for the latter device.

The WHO study ${ }^{6}$ included a comparison of the ML $250^{\circledR}$ with the TCu220C. Insertions were performed in 2000 parous women immediately after first trimester termination of pregnancy. At 3 years, event rates per 100 users were not significantly different, although the pregnancy rate of the ML250 ${ }^{\circledR}$ was higher. There were no ectopic pregnancies or perforations with either device. This arm of the study concluded that the ML250 ${ }^{\circledR}$ does not appear to offer any clinical advantage over the TCu220C.

A review article published in 1992 examined event rates with the Multiload devices in comparative and noncomparative studies. ${ }^{9}$ The conclusions were that the ML375 ${ }^{\circledR}$ performs better than the ML250 ${ }^{\circledR}$ in terms of pregnancy prevention, but that the T380A performed consistently better than the ML $375^{\circledR}$ in all studies reviewed. Furthermore, expulsion rates were not found to be lower than with T-shaped devices. Ectopic, perforation and pelvic infection rates were similarly low in Multiload users as in T-shaped device users. The author also concluded that the Multiload devices may perform better in nulliparous women than T-shaped copper devices due to their smaller width, although there is no objective evidence that this is the case.

Subsequently, a 3-year randomised comparative trial comparing the ML375 ${ }^{\circledR}$ to the TCu380A in parous women found that the cumulative pregnancy rates for both devices were acceptably low at 2.9 and 1.6 , respectively. ${ }^{10}$ The authors concluded, however, that the fact that the rate of the TCu380A was significantly lower made this the device of choice. Expulsion rate, again, was not found to be lower with the ML $375^{\circledR}$. Thiery et al., in a non-comparative study, found the 5-year failure rate of the ML $375^{\circledR}$ to be 2.9. ${ }^{11}$

In conclusion, although the ML $375^{\circledR}$ performs well in pregnancy prevention, its efficacy is lower than that of the TCu380A in most studies. In addition, the claims that the design would minimise the risk of expulsion have not been borne out in clinical trials.

\section{The Nova T series}

The Nova T200 ${ }^{\circledR}$ has been in use since 1978 . It consists of a plastic T-shaped frame with silver-cored copper wire wound around its central stem, presenting a total surface area of $200 \mathrm{~mm}^{2}$ copper. The addition of the silver core was found to reduce fragmentation, thus prolonging the effective lifespan of the device. In the early 1990s, a higher load but otherwise identical device, the Nova T380 ${ }^{\circledR}$ was developed, bearing a surface area of $380 \mathrm{~mm}^{2}$ copper. This was in response to poorer performance of the Nova T $200^{\circledR}$ in clinical trials comparing it with devices with $>250 \mathrm{~mm}^{2}$ of copper. Distribution of the Nova $\mathrm{T} 200^{\circledR}$ ceased in October 2001.

The Nova T200 ${ }^{\circledR}$ has been extensively studied, but perhaps one of the most important trials conducted was by the WHO, ${ }^{6}$ with double the women-months of use compared with the other trials. Comparison between the Nova T200 ${ }^{\circledR}$ and the $\mathrm{TCu} 220 \mathrm{C}$ showed the Nova $\mathrm{T} 200^{\circledR}$ to perform significantly less well in intrauterine pregnancy prevention at 3 and 5 years in over 1800 insertions. The 5-year cumulative failure rate for the Nova $\mathrm{T} 200^{\circledR}$ was 12.3 . The inferior efficacy was particularly marked after the third year, leading to the trial being halted at 5 years. Other studies have also found the Nova $\mathrm{T} 200^{\circledR}$ to be less effective than a variety of other devices, with no significant difference in adverse event rates. ${ }^{12,13}$

More favourable results have also been reported in smaller studies. A non-comparative study carried out by the UK Family Planning Research Network found the failure rate at 3 years to be 3.0 per $100 .{ }^{14}$ A Norwegian trial reported no significant difference in failure rates between the Nova T200 ${ }^{\circledR}$, ML $375^{\circledR}$ and ML250 ${ }^{\circledR} .15$ However, both studies involved fewer women and a shorter follow-up period than the WHO study.

The overall balance of evidence is that the efficacy of the Nova $\mathrm{T} 200^{\circledR}$ is lower than that of other currently available devices; contraceptive efficacy has been observed to be enhanced by increasing the amount of copper to $>300 \mathrm{~mm}^{2}$. Many family planning providers had already abandoned the low-dose copper devices for long-term use. A suitable use for remaining stocks of devices might be as emergency use in women planning removal at the next menstrual period. The small inserting diameter of only $3.7 \mathrm{~mm}$ when loaded into the inserter tube usually allows easy negotiation of the cervical canal.

A non-comparative study of the Nova $\mathrm{T} 380^{\circledR}$ in 400 parous women reported a 2-year cumulative pregnancy rate of 1.6, with no ectopic pregnancies. ${ }^{16}$ One perforation occurred and the removal rate for bleeding, pain and 'other medical reasons' was 15 at 2 years. Expulsion rate was low at 2.8. A subsequent non-comparative study $^{17}$ by the UK Family Planning and Reproductive Health Research Network of routine clinical use (see pages 69-72 in this journal issue) showed a cumulative gross rate for pregnancy of 2.0 (95\% CI $0.9-3.9$ ) at 5 years. A total of 574 Nova T $380^{\circledR}$ devices were inserted, eight pregnancies occurred, all during the first 3 years of the study; two pregnancies were ectopic. Expulsion rates and removal rates for bleeding problems and bleeding with pain were higher than expected at 13.0 (CI 9.5-16.4) and 29.6 (CI 24.7-34.6), respectively, at 5 years. Whilst very encouraging, further data are needed about longer-term use and from a study directly comparing the Nova T380 ${ }^{\circledR}$ with the T380A.

\section{The Flexi-T300 ${ }^{\circledR}$ (Cu-Safe 300)}

This device, also known as the $\mathrm{Cu}-\mathrm{Safe} 300$, was developed specifically to decrease the incidence of unwanted side effects such as bleeding, pain and expulsion. The plastic 
frame of the device is smaller and more flexible than most other framed devices. The side arms are thinner than the central stem, allowing easier insertion by a simple push-in technique, and are bent back on themselves in order to reduce trauma to the endometrium and to generate a fundalseeking force, with a view to enhancing retention in the uterine cavity. The device bears $300 \mathrm{~mm}^{2}$ copper on its central stem.

Early studies were encouraging. In a non-comparative study in over 1000 women, $80 \%$ nulliparous, the 1-year pregnancy and expulsion rates were both 0.6 per 100 . Removals for bleeding and pain were also low, at 4.2 and 1.5 per 100 , respectively. ${ }^{18}$ However, a randomised trial comparing the device to the T380A in 600 nulliparous and parous women produced a higher pregnancy rate which was not significant, and a significantly higher expulsion rate for the $\mathrm{Cu}-\mathrm{Safe}$ than the T380A. ${ }^{19}$ The removal rates for bleeding and pain were significantly lower in the $\mathrm{Cu}-\mathrm{Safe}$ group and there were no perforations. The authors conclude that the $\mathrm{Cu}-\mathrm{Safe}$ presents both advantages and disadvantages when compared to the T380A. Insertion and removal are very much easier, perhaps making this a suitable device for insertion by paramedical personnel in developing countries. They also comment that, although too few for statistical analysis, event rates did not differ between nulligravid/nulliparous and parous women.

Another advantage of this device in the UK is its low price. This, together with ease of insertion and removal, may make the device a suitable option as emergency contraception where short-term use is intended, where insertion with another device has failed due to discomfort or inability to negotiate the cervical canal, or where other devices have caused undue discomfort.

\section{The GyneFix ${ }^{\circledR}$}

The GyneFix ${ }^{\circledR}$ device was introduced into the UK in 1997. It is a frameless copper-bearing device, designed to reduce the incidence of bleeding, pain and expulsion seen with framed devices. It is marketed as being a reliable alternative to hormonal contraception for all women, including nulliparous women, in whom there may be incompatibility between the size of uterine cavity and the frame of a standard device, causing discomfort, bleeding and expulsion. Clinical trials have confirmed that the GyneFix ${ }^{\circledR}$ is effective and acceptable to nulliparous as well as parous women, ${ }^{20}$ although to date there have been no published randomised trials involving nulliparous women.

An earlier model called Flexigard (identical to GyneFix ${ }^{\circledR}$ in all but insertion instrument) was found, in two randomised comparative studies, to have significantly higher rates of expulsion than the TCu380A in parous women. ${ }^{21,22}$ Shortcomings in the insertion instrument were identified and the modified device was named GyneFix ${ }^{\circledR}$.

Studies using the GyneFix ${ }^{\circledR}$ have been more encouraging. The 3-year expulsion rate in a noncomparative trial involving both nulliparous and parous women was 0.7 per $100 .^{20} \mathrm{~A}$ randomised comparative trial in parous women in China found the expulsion rate with the GyneFix $^{\circledR}$ to be significantly lower (3.0) than that of the framed device, the T380A (7.4), at 3 years. ${ }^{23}$ The authors state that most expulsions with GyneFix ${ }^{\circledR}$ occur within 3 months of insertion, representing 'insertion failures' due to insufficient implantation of the anchoring knot into the fundal myometrium through lack of experience with the technique. There were no pregnancies with the GyneFix ${ }^{\circledR}$ and only one with the T380A, confirming the high efficacy of both devices. A recent paper reported no expulsions in a non-comparative study using the device immediately postabortion in 175 Chinese women, mostly parous. ${ }^{24}$

Experience in routine family planning practice in the UK has confirmed high levels of user satisfaction with the GyneFix ${ }^{\circledR}$, including in nulliparous women, ${ }^{25}$ but has failed to reproduce the low expulsion rates seen in the clinical trials. A recent report on expulsions in the first 1000 users in Liverpool found the overall rate to be $7.6 \%$, most occurring within the first 3 months. Some of these may have been due to insufficient implantation of the anchoring knot into the fundal myometrium or relative inexperience with a technique, which has quite a marked learning curve. Expulsions continued to occur as late as 30 months after insertion; the reason for these is unclear. Specific training and continuing experience is considered essential in retaining expertise. ${ }^{26}$

The GyneFix ${ }^{\circledR}$ insertion instrument has recently been substantially changed in attempt to simplify insertion. Anecdotal experience suggests that this has indeed made the process easier, which may result in fewer expulsions.

Only one ectopic pregnancy has been reported with the GyneFix $^{\circledR}$, in the third year of use in a multicentre trial. ${ }^{21}$ None have yet been reported in the UK. The low intra- and extrauterine pregnancy rates may be due to the fact that the copper is held against the fundus by the anchoring mechanism, so that the highest concentration of copper ions is in the upper uterus.

No uterine perforations were reported in the clinical trials. However, after its introduction into Europe, a 'small number' of perforations (7/5000 insertions) were reported and were ascribed to inexperience of the clinician, improper technique or pathological conditions. ${ }^{27}$ Twelve perforations have been reported since its introduction to the UK out of an estimated 8000 devices inserted. The rate for framed IUDs is around 1.3 per $1000 .^{28}$ The place of GyneFix ${ }^{\circledR}$ has not yet been fully established. A randomised comparative trial comparing the GyneFix ${ }^{\circledR}$ to a framed device in nulliparous women is needed before its suggested role in nulliparous women can be evaluated fully.

\section{The levonorgestrel-releasing intrauterine system} (LNG IUS)

The LNG IUS (Mirena ${ }^{\circledR}$ ) is currently the only hormonereleasing intrauterine device available in the UK. It releases $20 \mu \mathrm{g}$ levonorgestrel per day and is licensed for 5 years' use, although efficacy to 7 years has been demonstrated. ${ }^{29}$ It is identical in design to the Nova T series, with a slightly wider inserter tube to avoid damage to the progestogen reservoir. The insertion instrument has recently been changed to allow a simple one-handed technique.

Many studies, reporting more than 12000 women-years of use, have confirmed the excellent efficacy of the LNG IUS with Pearl indices of $0-0.3 .^{13,29}$ There is no statistically significant difference between the efficacy of the LNG IUS and CuT380 at 7 years. ${ }^{30}$ A European multicentre trial showed an incidence of ectopic pregnancy of only 0.02 per 100 women-years, ${ }^{13}$ representing an $80-90 \%$ reduction in risk compared with women not using contraception. Approximately $20 \%$ of conceptions with the LNG IUS are ectopic, ${ }^{13}$ the possibility of ectopic pregnancy should not be ignored in a woman with a LNG IUS in situ. Expulsion rates have been found to be similar to that of other framed devices. ${ }^{30}$

The intrauterine release of levonorgestrel has a local effect on the endometrium, rendering it suppressed and insensitive to oestradiol, resulting in a progressive reduction in the volume and duration of menstruation. 
Menstrual irregularity, mostly frequent, irregular spotting is common in the first few months after LNG IUS insertion. From the fourth month onwards a profound reduction in menstrual blood loss (MBL) is typical. With increasing duration of use an increasing number of women become amenorrhoeic. Around $25 \%$ of women are amenorrhoeic at 5 years. Amenorrhoea is an expected and benign end-organ response to intrauterine levonorgestrel and is associated with normal circulating oestrogen levels.

The LNG IUS is the most effective pharmacological treatment for menorrhagia. Open studies of MBL consistently show reductions of $90 \%$ or greater; 31,32 comparative studies have shown higher efficacy than nonsteroidal anti-inflammatory drugs (NSAIDs) ${ }^{33}$ and norethisterone. ${ }^{34}$ The reduction in MBL results in an increase in haemoglobin concentration over the 5-year lifespan of the LNG IUS. ${ }^{13,35}$ Mirena ${ }^{\circledR}$ has recently received a licence in the UK for the treatment of idiopathic menorrhagia.

The tissue concentration of LNG in the endometrium during LNG IUS use far exceeds that found with high systemic doses of levonorgestrel. This explains the marked endometrial suppression seen in all layers of the endometrium, to the myometrium, and throughout the uterine cavity and the oligo-amenorrhoea seen with continuous oestrogen replacement in peri- and postmenopausal women. ${ }^{35-38}$ The LNG IUS is likely to be licensed in the UK for the provision of the progestogen element of hormone replacement therapy within the next 12 months.

Appropriately detailed pre-insertion counselling (including discussion about efficacy, insertion procedure, lifespan, bleeding pattern, expulsion, perforation, pelvic infection and ectopic pregnancy) is necessary prior to all IUD insertions. In the case of the LNG IUS the likely bleeding pattern with oligo-amenorrhoea following 3-4 months of frequent light bleeding needs emphasising. A recent systematic review showed a higher rate of discontinuation for menstrual disturbance among women with the LNG IUS than women using copper IUDs with $>250 \mathrm{~mm}^{2}$ copper. ${ }^{39}$ The authors highlighted the importance of counselling about menstrual change with the LNG IUS, so that women worried about side effects may choose to use a different method, and commented that discontinuation rates for amenorrhoea are greatly influenced not only by cultural factors but also by provider attitudes. An epidemiological study of 17360 LNG IUS users $^{40}$ performed to determine the overall continuation rates of the LNG IUS in normal use and to evaluate the symptoms associated with removal, showed 1-, 2-, 3-, 4- and 5-year continuation rates for the LNG IUS of $93,87,81,75$ and $65 \%$, respectively. The Pearl index over 5 years of use was 0.18 . The risk of premature removal of the LNG IUS was significantly lower in women who had an occasional or total absence of menstruation (relative risk $0.46,95 \%$ CI $0.43-0.50$ ) indicating the acceptance of the benign nature of oligo-amenorrhoea with adequate explanation.

The obvious use for the IUS is for women who suffer heavy periods, regardless of parity.

\section{Intrauterine devices and pelvic infection}

Pelvic infection is a much-feared and misunderstood condition. Pelvic inflammatory disease (PID) leading to tubal occlusion and infertility has been blamed on IUD use and has resulted in this method being withheld from nulliparous women. The relationship between the IUD and PID was clarified by a review published in $1992 .{ }^{41}$ This showed that:
- The risk of PID is increased above the background rate in the first 20 days after device insertion, thereafter dropping to that of the background population rate.

- The incidence of PID among IUD users reflects the background prevalence of sexually transmitted infection (STI), showing geographical variation and being higher in younger users, in whom STIs are known to be more prevalent.

- Type of device does not influence the incidence of PID (with the exception of the Dalkon Shield, now withdrawn).

- No cases of PID were seen in Chinese users, where mutual monogamy was said to be the norm.

More recently, a systematic review has provided further confirmation that infection is related to the insertion process in the presence of STI, after which PID rates drop to that of women not using contraception. In addition, there is no evidence that treatment of PID with the device in situ impairs response to treatment or that past use of an IUD leads to a higher risk of infertility compared with non-users. ${ }^{42}$

Users of hormonal methods of contraception benefit from the protective effect of progestogen on cervical mucus, reducing ascent of infection. Some workers have demonstrated a lower incidence of PID in IUS users (after the initial 20 days) thought to be through the same mechanism, ${ }^{13}$ though other studies have failed to confirm this. These findings support the view that IUD insertion may result in spread of a silent undetected infection from the lower to the upper genital tract. This is almost exclusively an STI, most commonly Chlamydia trachomatis in the UK. Women who are free of STI at insertion and remain in mutually monogamous relationships are at very low, if any, risk of PID and subsequent tubal infertility.

It is the presence of an STI that influences the risk of development of PID and not parity or age per se. This needs to be addressed in pre-insertion counselling, together with the recommendation to take a sexual history to assess risk for STIs and to consider tests for, at least, C. trachomatis. Ideally results should be available prior to insertion; in postcoital insertions appropriate antibiotic 'cover' can be used. Partner notification and treatment is necessary when the test is positive.

A study published in $2001^{43}$ suggested that long-term IUD use in nulliparous women is associated with increased risk of fertility impairment, but that use for less than 6 years carries no such risk. Potential sources of bias (age, weight, smoking habits, expressed desire for children and lack of screening for STI or investigation of tubal patency amongst the IUD users) have been identified, ${ }^{44}$ and further comment on these findings is anticipated.

\section{Past history of ectopic pregnancy: IUD or not?}

High-dose copper IUDs and the IUS work mainly through preventing fertilisation, thus most extra- as well as intrauterine pregnancies will be prevented. The annual incidence of ectopic pregnancy for these devices is approximately 0.03 per 100 users. ${ }^{45}$ The annual pregnancy rate is an order of magnitude higher; for every ten intrauterine pregnancies, there will be approximately one ectopic pregnancy. The incidence for non-contraceptors is 1 in 100. Therefore, although IUD users are less likely to suffer an ectopic than those not using any method, the proportion expected in IUD failure is higher.

Women who have suffered an ectopic pregnancy in the past are at increased risk of having another. Although the high-dose copper IUD or IUS will reduce this likelihood, a 
low compliance method which acts by inhibiting ovulation (Depo-Provera or Implanon) would be ideal; however, either a high-dose copper IUD or the IUS may be appropriate options and use is not contra-indicated. There is no conclusive evidence that an IUS would be better than a T380A or GyneFix ${ }^{\circledR}$ if intrauterine contraception were to be used.

\section{Nulliparous women: what is the evidence?}

Device modifications have attempted to overcome problems perceived as being more prevalent in nulliparous users, namely bleeding, pain and expulsion. There is a paucity of data on IUD use in nulliparous women. The commonly-held belief that rates of expulsion and removal for bleeding and pain are generally higher in nulliparous women than parous is not well substantiated in recent literature, and lower rates have been observed by some workers. ${ }^{46-49}$ Intrauterine contraception should not be withheld from suitably selected and counselled nulliparous women who are at no risk, or free from, STI. Many requests for postcoital contraception are from young, nulliparous women for whom pregnancy would be a very unwelcome event. Reports of genuine failures of the copper IUD used postcoitally are very rare, with only eight documented failures in more than 8400 postcoital insertions. ${ }^{50}$ This method of postcoital contraception should be available to all requiring it, regardless of age or parity. Any copper-bearing device, but not the IUS, can be used as postcoital contraception; there are no data looking at the efficacy of individual devices.

\section{Cost-effectiveness of intrauterine methods}

Five years of the combined oral contraceptive pill cost between £61.97 and £174.09. Methods with higher use effectiveness cost $£ 98.58$ for 5 years of Depo-Provera and $£ 150$ for 5 years of Implanon (prices from British National Formulary, 2001). High continuation rates can be achieved with the LNG IUS in routine clinical practice and its very high use effectiveness makes it a cost-effective method, despite the initial financial outlay (£89.25). Copper IUDs represent the most incredible value for money, providing highly effective contraception for $£ 2-£ 5$ per year.

\section{Training in intrauterine techniques}

Individual IUDs have specific insertion techniques for which training is required. GyneFix ${ }^{\circledR}$ requires an insertion procedure unlike that for framed devices and requires extra specific training. The Faculty of Family Planning and Reproductive Health Care's Letter of Competence in Intrauterine Techniques is the recognised qualification in relation to intrauterine methods. All those providing intrauterine devices should audit their practice, perform sufficient insertions to maintain their skills and regularly update their knowledge.

\section{Conclusions}

Drawing together the evidence is a difficult task as different studies report different event rates for the same devices, either by statistical chance or due to differences in women recruited, and much early data about devices are from noncomparative studies.

The T380A (T Safe $380 \mathrm{~A}^{\circledR}$ in UK) remains the 'gold standard' copper device offering the best protection against pregnancy perhaps rivalled by the GyneFix ${ }^{\circledR}$, although larger and longer-term studies are needed to confirm this. Other framed high-dose copper devices offer slightly lower protection against pregnancy, with similar adverse event rates (Table 2). The GyneFix ${ }^{\circledR}$ may offer advantages over framed devices but only when problems with expulsion in routine use can be overcome. The LNG IUS is the appropriate choice for women with heavy periods, either spontaneously or when using a copper IUD.

Table 3 Suggested preference order for the use of individual IUDs

Parous women with normal periods

T Safe $380 A^{\circledR}$

Nova T380 ${ }^{\circledR}$

GyneFix $^{\circledR}$

ML375 ${ }^{\circledR}$

Flexi-T300 ${ }^{\circledR}$

Nulliparous women with normal periods

GyneFix $^{\circledR}$

T Safe $380 A^{\circledR}$

Nova T380 ${ }^{\circledR}$

Flexi-T300 ${ }^{\circledR}$

Women with heavy periods/heavy periods with copper IUD LNG IUS (Mirena ${ }^{\circledR}$ )

Insertion difficulties encountered

Nova T380 ${ }^{\circledR}$

Flexi-T300 ${ }^{\circledR}$

GyneFix $^{\circledR}$

Emergency IUD/short-term use in young women

Nova T380

Flexi-T300 ${ }^{\circledR}$

Nova $\mathrm{T} 200^{\circledR}$ (whilst in-date stocks remain)

Based on efficacy data and the practical difficulties encountered as a result of the relatively wide insertion diameter of the T Safe $380 \mathrm{~A}^{\circledR}$, a suggested preference order for the use of IUDs is given in Table 3.

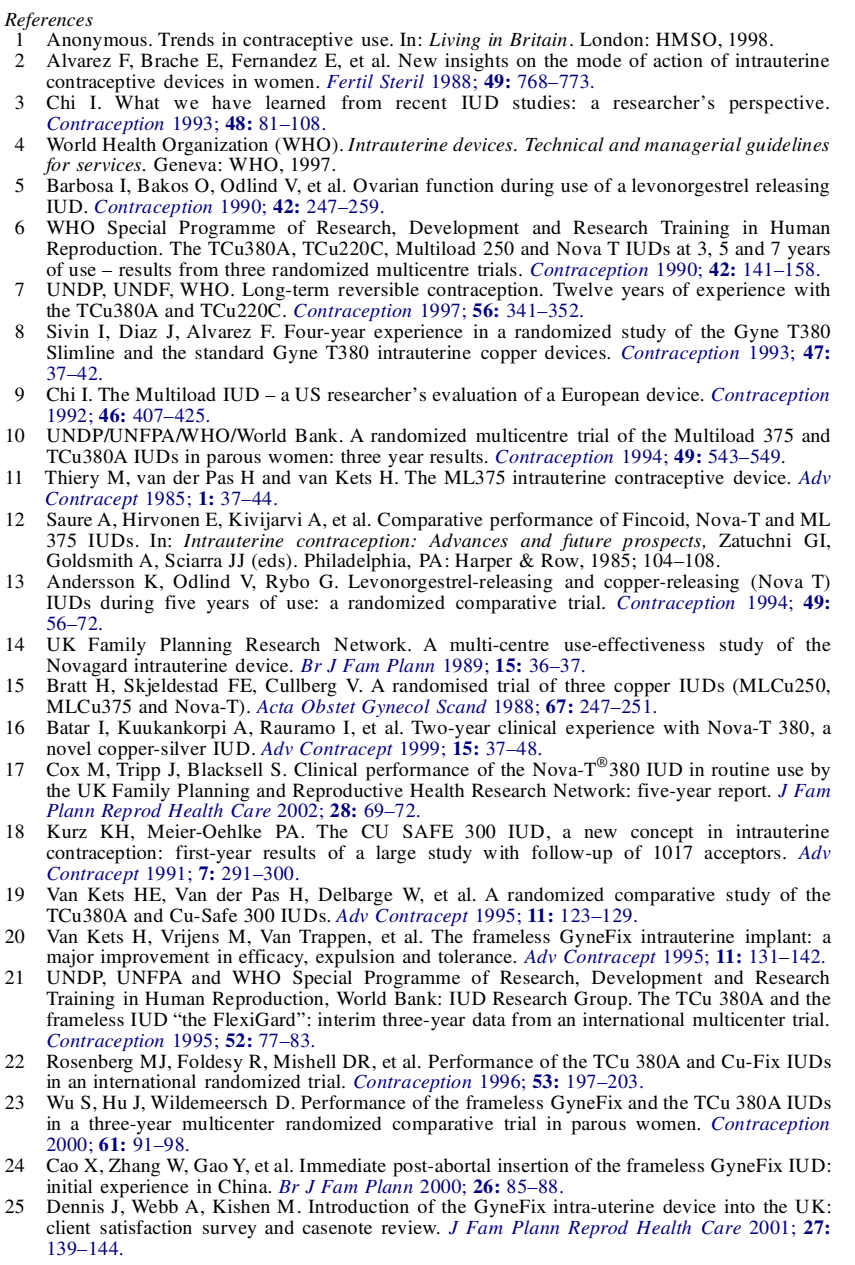

Trenc in contace Ant devices in women. Fertil Steril 1988; 49: 768-773.

earch Training in Human UNDP UNDF, WH the Fandomized nulticentre trials. Contraception 1990, 42: 141-158. 作

Sivin I, Diaz J, Alvarez F. Four-year experience in a randomized study of the Gyne T380 Slimline and the standard Gyne T380 intrauterine copper devices. Contraception 1993; 47:

1992; 46: 407-425. TCu380A IUDs in parous women: three year results. Contraception 1994; 49: 543-549. Thiery M, van der Pas $\mathrm{H}$ and

Andersson K, Odlind V, Rybo G. LeVu, PA. Harps \& Row, 1985; 104-108. (Nova T) IUDs during five

ess study of the

380 IUD in routine use by Network: five-year report. J Fam new concept in intrauterine the Van Kets HE Var

The frameless GyneFix intrauterine implant: ( Wold Bank: IUD Reserch Group. The TCu $380 \mathrm{~A}$ asd the Contraception 1995; 52: 77-83. Ronberg MJ, Foldesy R, Mishell DR, et al. Performance of the TCu 38 Women. Contraception ao X, Zhang W, initial experience in China. Br J Fam Plann 2000; 26: 85-88.

client satisfaction survey and casenote review. J Fam Plann Reprod Health Care 2001; 27: $39-144$. 
6 Dennis J, Webb A, Kishen M. Expulsions following 1000 GyneFix insertions. J Fam Plann Reprod Health Care 2001; 27: 135-138.

A, GyneFIX. The frameless intrauterine contraceptive implant - an update. Br J Fam Plann 1999: 24: 149-159.

Population Reports. IUDs - An update. Series B, Number 6. Geneva: World Health Pruaization December 1995.

Sivin I Sten J. Heath duing prolonged use of levonorgestel 20 meg/d and the Copper TCu Sive Sivin I, Stern J, Coutinho E et a Pronged intruterine controption - 7 year sudy of


lentro Obstet Gymacol 1990; $97: 690-694$.

Rybo G. Tratment of menorhagia in Chinese women: efficacy versus acceptability.

Milsom I, Andersson K, Andersch B, et al. A comparison of flurbiprofen, tranexamic acid and a levonorgestrel-releasing intra-uterine contraceptive device in the treatment of idiopathic menorrhagia. Am J Obstet Gynecol 1991; 164: 879-883.

Irvine GA, Campbell Brown MB, Lumsden MA, et al. Randomized comparative trial of the levonorgestrel intrauterine system and norethisterone for treatment of idiopathic menorrhagia. Br J Obstet Gynecol 1998; 105: 592-598.

35 Sivin I, El-Mahgoub S, McCarthy T, et al. Long-term contraception with the levonorgestrel 20 mcg/day ( $\mathrm{LNg}$ 20) and the Copper TCu380Ag intrauterine devices; a five year-randomised study. Contraception 1990; 42: 361-376.

36 Andersson K, Mattsson L-O, Rybo G, et al. Intrauterine release of levonorgestrel - a new way of adding progestogen in hormone replacement therapy. Obstet Gynecol 1992, 79: 963-967. Suhonen S, Allonen H, Lahteenmaki P. Sustained-release oestradiol implants and a levonorgestrel-releasing intrauterine device in hormone replacement therapy. Am J Obstet Gynecol 1995; 172: 562-567.
38 Suhonen S, Holmstrom T, Lahteenmaki P. Three-year follow-up of the use of a levonorgestrelreleasing intrauterine system in hormone replacement therapy. Acta Obstet Gynecol Scand

39 French RS. Cowan FM, Mansour D, et al. Levonorgestrel-releasing $(20 \mathrm{mcg} / \mathrm{day})$ intrauterine systems (Mirena) compared with other methods of reversible contraceptives. Br J Obstet 00; 107: $1218-1225$.

40 Backman T, Huhtala S, Blom T, et al. Length of use and symptoms associated with premature removal of the levonorgestrel intrauterine system: nation-wide study of 17,360 users. $B r J$ Obstet Gynaecol 2000: 107: 335-339.

41 Farley T, Rosenberg M, Rowe P, et al. Intrauterine devices and pelvic inflammatory disease: an international perspective. Lancet 1992; 339: 785-788.

2 Grimes D. Intrauterine device and upper-genital-tract infection. Lancet 2000; 356: 1013-1019. Doll H, Vessey M, Painter R. Return of fertility in nulliparous women after discontinuation of the intrauterine device: comparison with women discontinuing other methods of contraception.

44 Grimes D. Intrauterine devices and infertility: sifting through the evidence. Lancet 2001; 358:

Sivin I. Dose and age-dependent ectopic pregnancy risks with intrauterine contraception. 78: $291-298$

Smith PR. Copper IUDs in nulliparous women. In: Medicated intrauterine devices, Hafez ESE, Van Os WAA (eds). Martinus Nijhoff, 1980; 119-126.

Petersen KR, Brooks L, Jacobsen B, et al. Intrauterine devices in nulliparous women. $A d v$ Contracept 1991: 7: 333-338.

48 Lete I, Morales P, de Pablo J. Use of intrauterine contraceptive devices in nulliparous women: personal experience over a 12-year period. Eur J Contracept Reprod Health Care 1998; 3: 190-193. Duenas J, Albert A, Carrasco F. Intrauterine contraception in nulligravid vs. parous women.
Contraception 1996; 53: 23-24.

50 Trussell J, Ellerton C. Efficacy of emergency contraception. Fertil Control Rev 1995; 4: 8-11.

\section{Discussion points}

1. What evidence is there that increasing the amount of copper increases the efficacy of the IUD?

2. Which device has the lowest expulsion rate?

3. Which device should be chosen for a nulliparous woman requesting emergency contraception?

4. Can intrauterine contraception be used for a woman with a history of ectopic pregnancy? Which device should be chosen?

5. How can PID be avoided in IUD users?

\section{F Faculty \\ A Aid to \\ C CPD \\ T Topics}

A CPD Self-Assessment Test QUESTION SHEET

To be reviewed not later than $30^{\text {th }}$ June 2007

\section{IUDs: Which device?}

\section{Indicate your answer by ticking the appropriate box for each question}

1. The T380A has been shown to be significantly more effective in preventing pregnancy than most other devices available in the UK.

2. High-dose copper IUDs act mainly by preventing fertilisation.

3. The Multiload devices have lower expulsion rates than other framed devices due to their unique shape.

4. The Nova $\mathrm{T} 380^{\circledR}$ has been shown in trials to be as effective as the T380A in preventing pregnancy.

5. The GyneFix ${ }^{\circledR}$ has been shown to cause fewer bleeding problems than framed IUDs in nulliparous women.

6. Low-dose copper IUDs should be avoided due to their lower contraceptive efficacy compared to high-dose devices.

7. Nulliparity is an independent risk factor for developing PID leading to tubal infertility in IUD users.

8. The LNG IUS has been shown to be superior to the CuT380A in women with a history of ectopic pregnancy.

9. The LNG IUS is suitable treatment for idiopathic menorrhagia.

10. The LNG IUS may be offered to women with heavy periods who request emergency contraception.

Turn to page 000 for answers 